
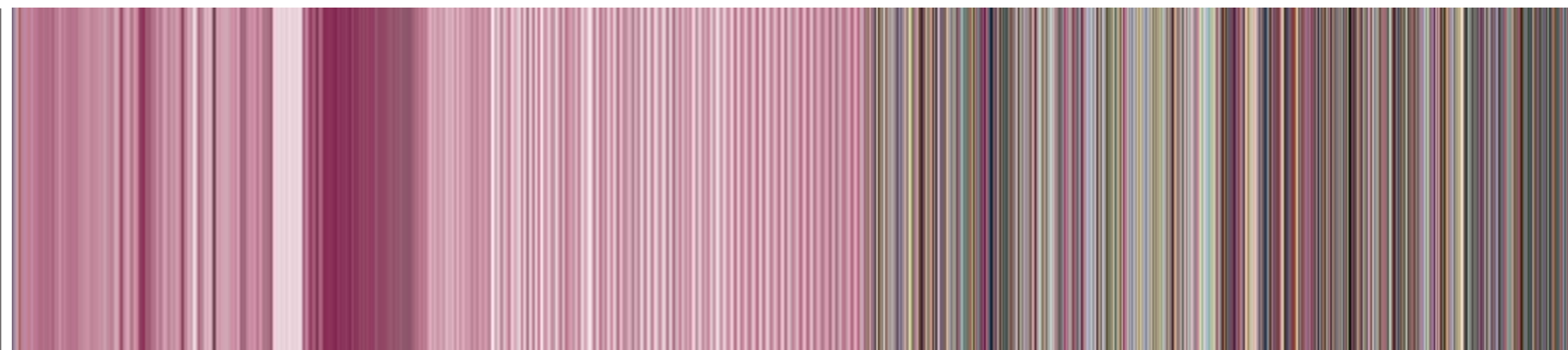

\title{
Seismic sleuths
}

\author{
The worldwide network of seismometers is detecting some surprising \\ events, from bouncing kangaroos to changes in climate. Larry O'Hanlon \\ talks to the seismologists who have found unusual uses for their data.
}

W hen Russia's Kursk submarine went down with all hands in the Barents Sea in August last year, no one rushed to call a seismologist. But, in January this year, it was researchers from that discipline who finally ended the debate over the cause of the disaster.

Keith Koper of the University of Arizona in Tucson reported that Baltic seismic stations had recorded tell-tale vibrations from explosions aboard the Kursk ${ }^{1}$. The evidence suggested that the tragedy was caused by one of the submarine's torpedoes accidentally detonating while the craft was on the surface - an event followed by several more simultaneous detonations at depth. Russian authorities had previously claimed that

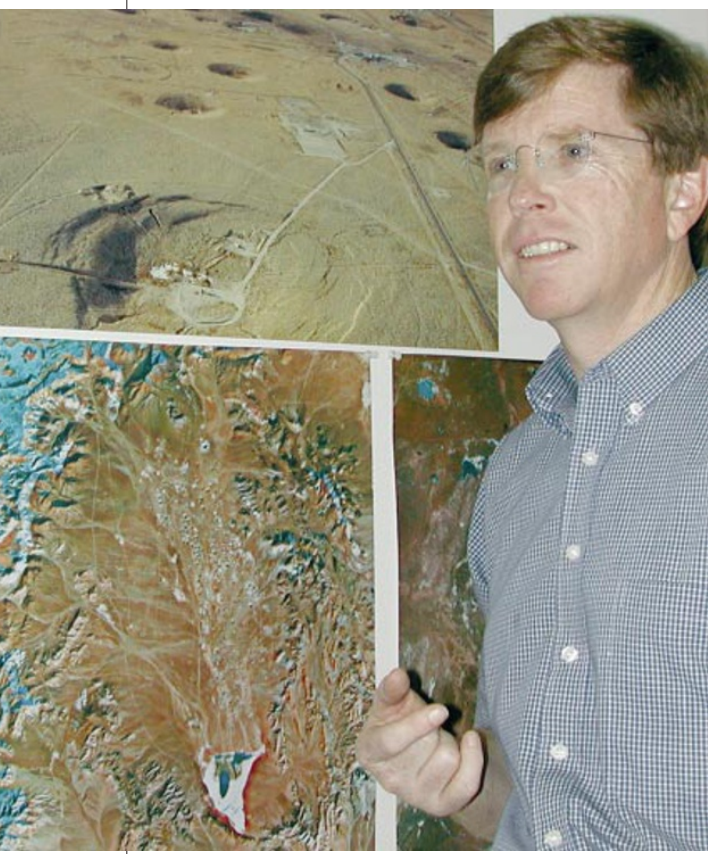

Ear to the ground: Terry Wallace's data disproved the claim that Iraq had tested a nuclear bomb. a collision with an unidentified foreign submarine was to blame.

Koper's Kursk paper is just one example of the unexpected uses that researchers are finding for seismological data. A global network of seismometers, established to study earthquakes and to watch out for states testing nuclear weapons, is allowing scientists to listen in on phenomena as diverse as the sonic boom created by the space shuttle as it returns to Earth, and the 'sounds' of global warming.

\section{Detective work}

Such unusual applications for seismometers came to light after what many consider to be the United States' worst home-front disaster of the Second World War. On 17 July 1944, around 5,000 tons of munitions accidentally detonated in a series of explosions at the US Navy's Port Chicago on the Sacramento River in California. The overall blast killed 320 sailors and flattened the port.

After the event, Navy officials consulted seismologist Perry Byerly of the University of California, Berkeley. The blast had registered on nearby seismometers, and Byerly was able to determine the exact timing and sequence of the different explosions ${ }^{2}$. Although Byerly had previously examined seismic signals from mine blasts ${ }^{3}$, the prominence of the Port Chicago disaster meant that, for the first

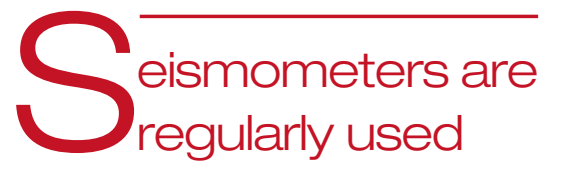

to verify claims that nuclear tests have taken place. time, the value of such analyses attracted widespread attention.

The drafting of the Comprehensive Test Ban Treaty (CTBT) in the 1950s propelled Byerly's work onto the global stage. The treaty, which was intended to outlaw all nuclear weapons tests, needed a mechanism by which breaches of the ban could be spotted. With this in mind, the US government in 1959 initiated the Worldwide Standardized Seismographic Network (WWSSN) as one strand of a range of strategies to spot nuclear tests. It consisted of 120 seismic stations - the first global seismic network. At the same time, the US government began pouring millions of dollars into basic seismological research, giving a tremendous boost to what was then, arguably, a peripheral field of study.

As WWSSN seismologists started to detect, measure and compile the world's earthquakes on their maps, the collected epicentres started to delineate the hitherto unknown boundaries of the Earth's crustal plates. "That really helped usher in the whole era of plate tectonics," says Terry Wallace, a seismologist at the University of Arizona and a member of the team that worked on the Kursk data. It was a case of sublime serendipity, with Byerly's basic research leading to a seismic network for monitoring nuclear blasts which, in turn, helped spur what proved to be the twentieth century's most significant theoretical shift in the Earth sciences.

More than 16,000 seismic stations now cover the globe. Originally, seismometers were sensitive only to vibrations at a particular frequency, so seismic stations had to use an array of different seismometers to monitor the range of vibrations that were of interest. But the development in the mid-1980s of broadband seismometers, which are sensitive to vibrations at a range of different 

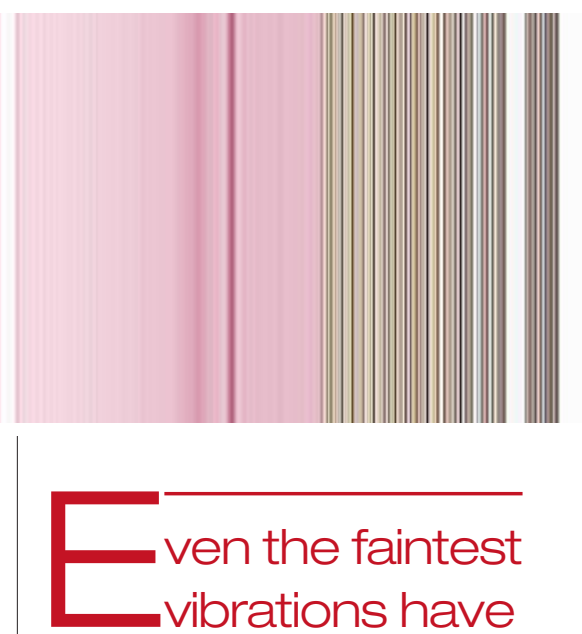
the potential to reveal seismic treasures.

frequencies, made it easier and cheaper to add new stations to the global network.

The seismometers constantly spot surprising events, from meteor impacts to rock falls or the long, slow, gravitational pull of the Moon on the Earth's crust. For the most part, these signals are a nuisance to seismologists. Noise from human activities is an increasing problem. People continue to spread over the surface of the Earth, bringing noisy machines with them. "It's what we call cultural noise," says Wallace. "Our problem is that we have an incredibly sensitive seismometer and people come and build around it."

\section{Noise annoys}

Seismologists are continually developing ways of separating the seismic wheat from the chaff. But once the interfering signals are identified and separated out, fresh uses for seismometers quickly emerge. "One man's noise is another man's signal," says Robert Uhrhammer, a seismologist at the University of California, Berkeley.

Traffic movement, for example, can sometimes be useful seismic noise. When the Yom Kippur war ended in 1973, Israel and Egypt were in dispute over tactically important passes through the Sinai mountains. Israel wanted to maintain its electronic listening station in the mountains, but the USmediated peace agreement called for Israeli withdrawal from the region.

A compromise was reached that allowed Israel to control the station remotely if it agreed to withdraw its forces from the area. The United States installed a monitoring system, of which seismic sensors where a part, to check for Israeli troop movements near the station. Without such a system, the peace agreement may never have been signed. More recently, similar systems have been developed by the US Immigration and Naturalization Service and International
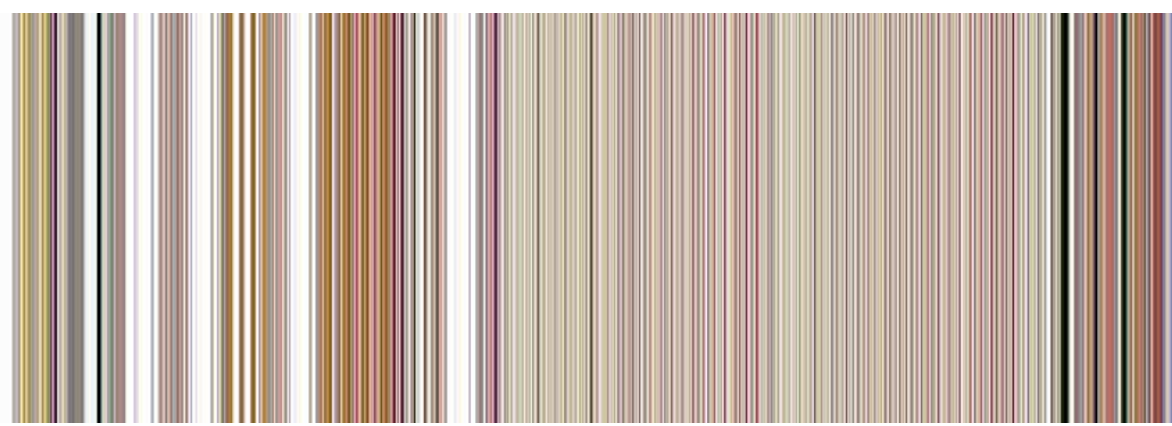

Microwave, a company in East Norwalk, Connecticut, to spot illegal immigrants trying to cross the border from Mexico.

Seismometers are also still regularly used to verify, or dismiss, claims that nuclear tests have taken place. Despite decades of diplomatic wrangling, the CTBT has yet to come into force. The list of signatories has some notable exceptions, such as India and Pakistan, both of which have atomic weapons programmes. And other nuclear powers, such as the United States and China, have signed but not ratified the treaty.

But if the treaty ever does come into play, a dedicated network of monitoring stations will be ready to deploy their seismometers to help watch for nuclear tests. Many seismometers are based at university laboratories, and over half are already supplying information to the Preparatory Commission for the Comprehensive Nuclear-Test-Ban Treaty Organization, the Vienna-based body charged with setting up the system that will monitor the CTBT should it come into force.

Shortly after his work on the Kursk, Wallace made the news again. With his Arizona colleagues, he investigated a report in a February edition of the British newspaper The Sunday Times which alleged that Iraq had carried out a clandestine test of a 10-kiloton nuclear weapon in September 1989. Wallace's team managed to debunk the story by looking at the seismological record for the region. An informant had told The Sunday Times that there had been an underground blast beneath Lake Rezazza, 150 kilometres southwest of Baghdad. But the seismological record contained no evidence of any significant seismic activity within $50 \mathrm{~km}$ of the lake that day.

Wallace concluded that even if Iraq had, as alleged, hollowed out a huge cavern under the lake to 'decouple' the blast from the surrounding rock, the detonation of a 10kiloton bomb could not have escaped seismic detection. Using data from decoupling experiments by the United States and the former Soviet Union as a guide, he worked out that such a blast would have caused a seismic signal with a magnitude of between 3.8 and 4.0 on the Richter scale. At the time, the seismometer network in the region was capable of detecting any signal with a magnitude of over 2.9. But only tiny seismic
Shakedown: as well as monitoring earthquakes, seismometers can be used to listen to waves, spot underground and undersea nuclear tests, detect the space shuttle or terrestrial traffic, view the Moon's gravitational pull on the Earth's crust, and work out the size of kangaroos.

signals were detected on the date of the alleged test - too weak even to verify their origins.

Just in case more tangible proof was needed, there is also some compelling circumstantial evidence: the continuing existence of Lake Rezazza. According to Wallace, "The collapse of a nuclear cavity under a lake would, of course, produce a tell-tale sudden drop in the water level, if not the disappearance of the lake - a risky proposition for a country attempting a clandestine test."

\section{Small is beautiful}

Even the faintest vibrations, known as microseisms, offer seismic treasures, says Peter Bromirski, a seismologist at the Scripps Institution of Oceanography in La Jolla, California. In the early 1990s, Bromirski was working on a postgraduate

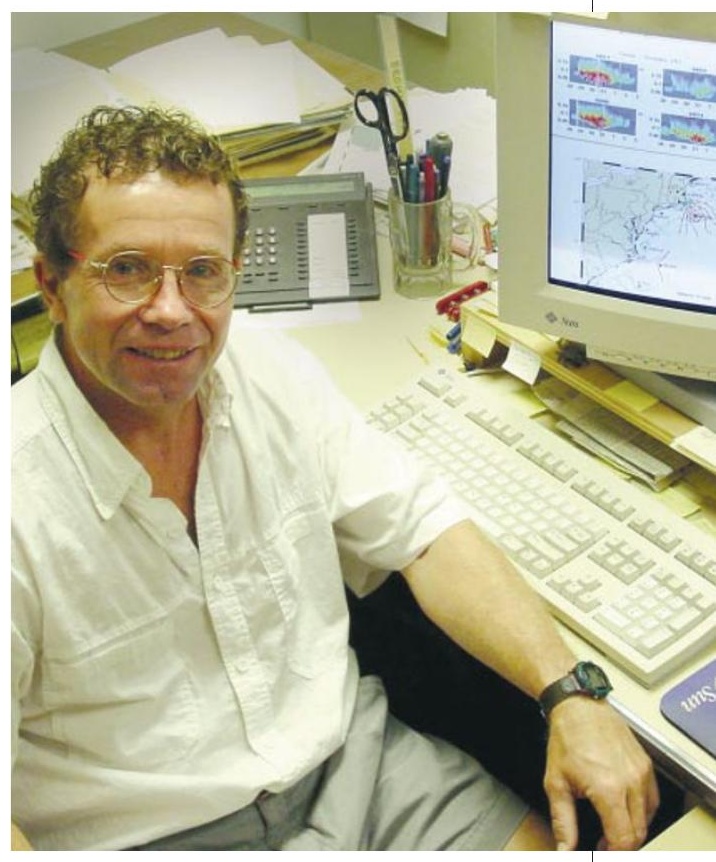

Making a splash: Peter Bromirski hopes to assess changing wave heights using seismic data. 
project for the US Navy to evaluate whether ocean-bottom seismometers could detect nuclear tests. The project is still classified, but Bromirski says that the system could have been used to monitor bomb tests in North Korea without invoking the political complications of trying to place land-based seismometers in neighbouring countries.

While processing US Navy data from seismometers placed off the coast of Oregon, Bromirski quickly realized the need to filter out ocean noises. Microseisms of ocean waves were among those noises, and he has been studying them ever since. It was a classic case of noise becoming signal, Bromirski says.

\section{Stormy relationship}

In 1999, Bromirski proposed that seismic data collected by stations along the California coastline could help fill in the gaps in climate data from the same area. Climate researchers were keen to look for long-term changes in wave heights, as many models of climate change predict that rising global temperatures will lead to more frequent storms, which would be reflected in an increase in wave heights. But ocean buoys, a key source of data on wave conditions, had only been deployed in the region since the early 1980s. By contrast, seismometers at the University of California, Berkeley, have been collecting data since about 1930 . Bromirski thought that the missing wave data might be lying hidden in the seismic records.

Ocean swells approaching a coastline push down on the seabed, resulting in distinctive microseisms that travel inland. Individual waves can also be detected as they hit land. By comparing records of these microseisms from land-based seismometers with data from ocean buoys, Bromirski and his colleagues worked out how to estimate wave heights using the seismic data ${ }^{4}$. Applying Bromirski's technique to the seismic archives could produce seven decades of wave-height data for the northeast Pacific Ocean.

Rather than analysing the whole 70-year record, Bromirski has since used the seismic record to tease out information from earlier storms and even the first great El Niño of

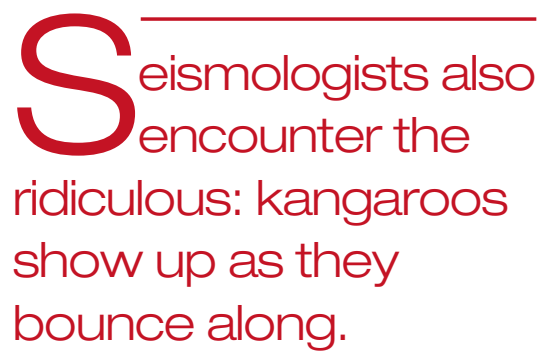

the twentieth century, that of 1940-41 (ref. 5). "Back then nobody really knows what the waves were like," he says. "There were no buoys and no satellites, just ship measurements and atmospheric pressure records."

Ingo Grevemeyer, a seismologist at the University of Bremen in Germany, is taking a similar approach. Using a 40-year record of microseisms from a seismic station in Hamburg, Grevemeyer has shown that the northeast Atlantic Ocean has become more stormy during the past 20 years ${ }^{6}$.

Of course, not everything forensic seismologists discover is so useful. With so much noise they also encounter the ridiculous. Kangaroos, for example, show up in the seismic record as they bounce along. "You can gauge the size of the kangaroo by the frequency of its bounces," says Uhrhammer, who has become an informal curator of seismic curiosities.

Uhrhammer has even used seismic noise to spot broken equipment. In 1999 he analysed seismic signals from a diesel generator that was powering scientific equipment on the Farallon Islands off San Francisco. Uhrhammer, an experienced mechanic, realized that one of the generator's pistons was misfiring and so was able to make repairs before the generator broke down completely.

\section{Distance learning}

Despite enjoying working with these quirks, the ultimate aim of most seismologists is still to filter them out. The best way to do that may be to escape the Earth altogether and use a network of satellite-based seismometers. Wallace proposes that a series of satellites could bounce electromagnetic signals off the Earth's surface to give realtime visualizations of, for instance, seismic energy moving along the San Andreas Fault. By moving around the Earth, the seismometers would be able to view the same point from different angles, building up a three-dimensional picture of the surface. The seismometers could watch seismic waves from an earthquake rippling over California as if the waves were from a stone dropped in a pond.

Wallace says that space-based seismometers could also monitor very slow changes in the Earth's surface that broadband seismometers miss - such as the gradual movement of the surface created by the hollowing out of underground caverns during mining activity.

Although a definite proposal has not yet been put together, and many technical challenges will have to be overcome, Wallace says that the idea has the backing of the seismological community. He believes the insights that seismologists would gain from studying quakes from such a viewpoint will lead to great advances in modelling fault zones. "I think it will revolutionize seismology," he says. "It will really allow us to see the groans of the Earth - a picture of a very dynamic planet. A picture of what's happening right now."

Larry 0'Hanlon is a science writer in Auburn, California.

1. Koper, K. D., Wallace T. C., Taylor, S. R. \& Hartse, H. E. Eos 82, $37,45-46$ (2001).

2. Byerly, P. Bull. Seismol. Soc. Am. 36, 331-348 (1946).

3. Byerly, P. \& Wilson, J. T. Bull. Seismol. Soc. Am. 25, 259-268 (1935).

4. Bromirski, P. D., Flick, R. E. \& Graham, N. J. Geophys. Res. 104, 20753-20766 (1999).

5. Bromirski, P. D. Geochem. Geophys. Geosyst. (in the press).

6. Grevemeyer, I., Herber, R. \& Essen, H.-H. Nature 408, 349-352 (2000).

\section{Web links}

Seismic analysis of the sinking of the Kursk http://www.geo.arizona.edu/researchers/kkoper/ Kursk/for_kursk.html

Detection of the space shuttle's sonic boom

http://www.galcit.caltech.edu/SonicBoom/

boomslides.pdf

Monitoring of Egypt-Israel peace accord

http://www.cmc.sandia.gov/issues/papers/vannoni2/ index.html

Debunking of alleged Iraqi nuclear test http://www.vertic.org/tnv/marapr01/iraq.html Details of the proposed Comprehensive Test Ban Treaty monitoring scheme

http://pws.ctbto.org 